\title{
Modeling of Regional Innovation Spillover Effects Based on DEA Malmquist Index
}

\author{
Anna A. Firsova*[0000-0002-8906-6326], Galina Yu. Chernyshova ${ }^{\dagger[0000-0002-6464-0408]}$ \\ Saratov State University, Saratov, Russian Federation \\ *a.firsova@rambler.ru, †cherny111@mail.ru
}

\begin{abstract}
The article presents the results of a study of innovative spillover effects using Data Envelopment Analysis (DEA) tools. The study is novel, in that an assessment methodology has been developed based on the Malmquist index and an output-oriented DEA model has been built to analyze the dynamics of the regional innovation system development. The development of innovative systems at the regional and national levels has been assessed, the Malmquist Index has been calculated, the characteristics of the regions have been determined taking into account the evaluation of spillover effects, and conclusions have been drawn on the dynamics of the development of innovative activities. The results of the study indicate the presence of positive innovative spillover effects over 2005-2017 in the Russian economy.
\end{abstract}

Index Terms-Non parametric Model, Data Envelopment Analysis, Malmquist Productivity Index, Regional Innovations System, Spillovers.

\section{INTRODUCTION}

The topicality of this work lies in the need to study innovative spillover effects of the diffusion of innovations and to obtain a formalized assessment of the impact of diffusion processes of innovations and their externalities on structural shifts and economic growth in regional innovation systems.

One of the methodological approaches to assessing the impact of innovative spillover effects of the diffusion of innovations on the Russian economy growth and the regional innovative development is the comparison of the invested resources and the results of innovative processes as well as evaluation of the quantitative and qualitative changes in the national economy structure over time. A relevant tool for evaluating and researching the comparative effectiveness of economic systems is the use of the Data Envelopment Analysis (DEA) method [1]

The purpose of this study is to develop new methods of economic and mathematical modeling for the diagnosis of regional structural changes, to evaluate the spillover effects of diffusion of innovations using the DEA Malmquist Index methodology.

To achieve this goal, the following problems have been solved:

- determination of the methods for evaluating innovative spillover effects and substantiation of indicators for mathematical model construction, generating a research sample based on the Russian regional data;

- development of a methodology for using the DEA Malmquist Index to evaluate innovative spillover effects;
- application of the developed tools for assessing the efficiency dynamics of the development of regional innovative systems of Russia from 2005 to 2012.

\section{TheORETICAL ANALYSiS}

Over the past 20 years of economic reforms in Russia, a course has been set for the development of innovations, large-scale structural transformations have been implemented in the higher education and science sector, and numerous scientific and technical programs have been initiated, funding for innovations was increased, in all sectors of the economy have undergone significant changes.

To substantiate the goals and nature of structural transformations, it is important to obtain a formalized assessment of the results of state innovation policy. Direct results are reflected in state statistical reporting. These are a number of indicators, such as patents, $R \& D$ expenses and other quantitative indicators [2], [3]. However, indirect results and effects in the form of structural changes are much more difficult to measure.

Spillover oriented approaches can be a tool for evaluating the public policy effectiveness. An innovative spillover as an overflow is the result of diffusion and transfer of technologies and innovations in the form of processes of intellectual property transfer, support of innovative enterprises, the mutual transfer of personnel between industry and the R\&D sector [4], [5].

The present study uses the DEA and Malmquist Index tools to compare the economic indicators of the research and innovation activity of the Russian Federation constituent entities over the 2005-2012 period in order to determine the direction and assess the nature of innovative spillover effects.

This approach assumes a non-specific set of indicators reflecting these indirect effects which would be statistically significant and available for the study.

\section{RESEARCH METHODOLOGY}

\section{A. Data}

To evaluate innovative spillover effects, indicators were used to assess the qualitative structural changes that occurred in the economy under the influence of state innovation policy. Systemic macroeffects in this area consist of structural changes and increased indicators of innovative activity expressed primarily in the growing share of high-tech products in the GRP structure, rise in the number of innovations introduced 
Malmquist Productivity Index. DEA is a linear programming methodology that uses input and output data for a group of homogeneous objects in order to build a piece-wise linear production frontier. The DEA provides estimation of the efficiency relative to the best practices under the condition that the technology is fixed at current level. To construct the frontier, linear programming problems are solved (for each object in the sample, a separate problem is formulated and solved). The degree of technical inefficiency of each object is defined as the distance between the observed data point and the frontier. DEA makes it possible to obtain quantitative evaluation of the analysable entities usually called decision-making units (DMU).

Currently there are different types of DEA models depending on orientation (input-oriented, output-oriented), returns to scale (constant return to scale (CRS), variable returns to scale (VRS)), distance function, frontier type and other aspects [10]. In input-oriented model, the DEA method constructs the frontier by searching for the maximum possible proportional reduction of input data with constant output levels for each object. In the output-oriented model, the DEA method dines the maximum proportional increase in production output under assumption fixed input levels. These two approaches give the same estimations of technical efficiency when applying CRS model, but are unequal in VRS model. In this research, we apply CRS model.

The Malmquist index is used to evaluate the technological efficiency obtained for relatively different sets of objects [11]. The Malmquist index measures the total factor productivity change of a DMU between two periods. It is defined as the product of a change in efficiency (catch-up) and technological change (shift of the border). A change in efficiency reflects the extent to which the DMU improves or deteriorates its effectiveness, while technological changes reflect a change in the frontiers of efficiency between two periods [12].

The total factor productivity (TFP) using the Malmquist index methods change between two data points (e.g., those of a particular region in two adjacent time periods) by calculating the ratio of the distances of each data point relative to a common technology. The Malmquist TFP change index in output-orientated DEA model between period $t$ and period $(t+1)$ is:

$$
\begin{aligned}
& M_{o}\left(y_{t+1}, x_{t+1}, y_{t}, x_{t}\right)= \\
& \quad=\left(\frac{d_{o}^{t}\left(x_{t+1}, y_{t+1}\right)}{d_{o}^{t}\left(x_{t}, y_{t}\right)} \cdot \frac{d_{o}^{t+1}\left(x_{t+1}, y_{t+1}\right)}{d_{o}^{t+1}\left(x_{t}, y_{t}\right)}\right)^{0.5},
\end{aligned}
$$

where $\left(x_{t+1}, y_{t+1}\right)$ and $\left(x_{t}, y_{t}\right)$ represent the input and output vector of the period $(t+1)$ and $t$, respectively, the notation $d_{o}^{t}\left(x_{t}, y_{t}\right)$ represents the distance from the period $t$ to the period $(t+1)$ technology.

A value of $M_{o}$ greater than 1 will indicate positive TFP growth from period $t$ to period $(t+1)$. A value of $M_{o}$ less than 1 indicates a TFP decline. $M_{o}$ is the geometric mean of two TFP indices. The first is evaluated with respect to period $t$ technology and the second with respect to period $(t+1)$
The methodology for assessing the dynamics of region innovative development and innovative spillovers is based on the application of the DEA model with the

All statistical indicators for all analyzed objects are translated into comparable values.

\section{B. DEA Malmquist Index Modeling}


such that

technology. Anquivalent decomposed form of the total factor productivity index [13], [14] is:

$$
\begin{aligned}
& M_{o}\left(y_{t+1}, x_{t+1}, y_{t}, x_{t}\right)=\frac{d_{o}^{t+1}\left(x_{t+1}, y_{t+1}\right)}{d_{o}^{t}\left(x_{t}, y_{t}\right)} \times \\
& \times\left(\frac{d_{o}^{t}\left(x_{t+1}, y_{t+1}\right)}{d_{o}^{t}\left(x_{t}, y_{t}\right)} \cdot \frac{d_{o}^{t+1}\left(x_{t+1}, y_{t+1}\right)}{d_{o}^{t+1}\left(x_{t}, y_{t}\right)}\right)^{0.5} .
\end{aligned}
$$

Let's consider the first factor in (2) named as technical efficiency change $(E F F C H)$ :

$$
E F F C H=\frac{d_{o}^{t+1}\left(x_{t+1}, y_{t+1}\right)}{d_{o}^{t}\left(x_{t}, y_{t}\right)} .
$$

$E F F C H$ is the change in the output-oriented measure of technical efficiency between periods $t$ and $(t+1)$, it shows how the ratio of actual outputs to potential has changed. EFFCH indicates the capability of a $D M U$ to catch up with more efficient $D M U$ s.

The second factor in (2) is technological change (TECHCH):

$$
T E C H C H=\left(\frac{d_{o}^{t}\left(x_{t+1}, y_{t+1}\right)}{d_{o}^{t}\left(x_{t}, y_{t}\right)} \cdot \frac{d_{o}^{t+1}\left(x_{t+1}, y_{t+1}\right)}{d_{o}^{t+1}\left(x_{t}, y_{t}\right)}\right)^{0.5} \text {. }
$$

TECHCH is the potential index, the geometric mean of two relations, which characterizes the shift of the potential technology frontier between period $t$ and $(t+1)$. In other words, the last relation reflects a change in the technological efficiency of the evaluated object caused by a shift in the effective boundary.

The TFP index can be represented in the form of such factors as the change in efficiency and the technical change. Let for a time period $t, t=1, \ldots, T, D M U_{i}, i=1, \ldots, N$, use $P$ inputs to produce $S$ outputs. In a particular time period $t$ let's define:

$y_{i}$ is a $S \times 1$ vector of output quantities for the $D M U_{i}$;

$x_{i}$ is a $P \times 1$ vector of input quantities for the $D M U_{i}$;

$Y$ is a $N \times S$ matrix of output quantities for all $\mathrm{N} D M U_{i}$;

$X$ is a $N \times P$ matrix of input quantities for all $N D M U_{i}$;

$\lambda$ is a $N \times 1$ vector of weights;

$\phi$ is a scalar.

To calculate $M_{o}\left(y_{t+1}, x_{t+1}, y_{t}, x_{t}\right)$, it is necessary to solve the following linear programming problems [15]:

$$
\left(d_{o}^{t}\left(x_{t}, y_{t}\right)\right)^{-1}=\max _{\phi, \lambda} \phi
$$

such that

$$
\begin{gathered}
-\phi y_{i, t}+Y_{t} \lambda \geq 0, \quad-x_{i, t}+X_{t} \lambda \geq 0, \quad \lambda \geq 0 ; \\
\left(d_{o}^{t+1}\left(x_{t+1}, y_{t+1}\right)\right)^{-1}=\max _{\phi, \lambda} \phi,
\end{gathered}
$$

such that

$$
\begin{gathered}
-\phi y_{i, t+1}+Y_{t+1} \lambda \geq 0, \quad-x_{i, t+1}+X_{t+1} \lambda \geq 0, \quad \lambda \geq 0 \\
\left(d_{o}^{t}\left(x_{t+1}, y_{t+1}\right)\right)^{-1}=\max _{\phi, \lambda} \phi
\end{gathered}
$$

$$
\begin{gathered}
-\phi y_{i, t+1}+Y_{t} \lambda \geq 0, \quad-x_{i, t+1}+X_{t} \lambda \geq 0, \quad \lambda \geq 0 ; \\
\left(d_{o}^{t+1}\left(x_{t}, y_{t}\right)\right)^{-1}=\max _{\phi, \lambda} \phi,
\end{gathered}
$$

such that

$$
-\phi y_{i, t}+Y_{t+1} \lambda \geq 0, \quad-x_{i, t}+X_{t+1} \lambda \geq 0, \quad \lambda \geq 0 .
$$

Tasks (5)-(8) must be calculated for each $D M U$ in the sample. Hence the total number of linear programming problems for $N$ DMUs and $T$ time periods is $N \cdot(3 T-2)$.

\section{Results}

Analysis of Malmquist productivity index and decomposition results from data of 80 regions of the Russian Federation allow present the tendency of regional innovation system development (Table I, Table II). The Table I contains regions with Malmquist index greater than 1 $\left(M_{o}>1\right)$.

The Table II contains regions with Malmquist index greater than $1\left(M_{o}<1\right)$.

The results (Table I) demonstrate a progress respectively productivity improvement in 47 regions (58.75\%) during this period. 33 regions $(41.25 \%)$ show productivity decline (regress) during investigated time period (Table II).

Analysis the evolution of the same DMUs over time involves calculating national average ratings (Fig. 1). The decomposition into the two components additionally demonstrates that the part of the improvement was attained through the technical change, rather than through the efficiency change of the relatively inefficient regions catching up with efficient ones. The national average for the total factor productivity of 80 regions is 1.128 , which is greater than 1; total factor productivity is growing and the growth rate is $12.8 \%$. It denotes that the technical efficiency reduces the difference with the optimal region on the frontier.

If $E F F C H>1$, it denotes that the technical efficiency reduces the difference with the optimal DMU. If $E F F C H<$ 1 , the technical efficiency increases the difference with the optimal DMU. The national average technical efficiency change index is 0.276 , less than 1 . It objectively indicates that the gap between the level of innovative systems development has significantly increased by the regions during the selected time period.

The technological change index $\mathrm{TECHCH}$ denotes the degree of technical advancement or technical innovation. If $\mathrm{TECHCH}>1$, it means the technical advancement, and $\mathrm{TECHCH}<1$ represents the technology possesses recessionary tendency. As seen from index decomposing, the national average of the technological change index is 4.081, greater than 1.

In order to measure how productivity divergences between region innovation systems change in 2012-2017 we identified three types of regions depending on the growth rate (Table III). Some of the regions $(32.50 \%)$ demonstrate relatively low rates of region innovation system development, and $26.25 \%$ of the 
Table II

MALMQUIST INDEX MEANS FOR THE REGIONS WITH DESCENDING PRODUCTIVITY

\begin{tabular}{|c|c|c|c|}
\hline Region & EFFCH & $\mathrm{TECHCH}$ & $M_{o}$ \\
\hline Republic of Sakha (Yakutia) & 0.146 & 6.742 & 0.982 \\
\hline Chukotka Autonomous region & 1.000 & 0.948 & 0.948 \\
\hline Republic of Buryatia & 0.162 & 5.811 & 0.943 \\
\hline Vladimir region & 0.120 & 7.671 & 0.917 \\
\hline Voronezh region & 0.121 & 7.526 & 0.909 \\
\hline Republic of Karelia & 0.167 & 5.305 & 0.884 \\
\hline Tambov region & 0.132 & 5.839 & 0.770 \\
\hline Sakhalin region & 0.292 & 2.595 & 0.758 \\
\hline Omsk region & 0.087 & 8.446 & 0.737 \\
\hline Ryazan region & 0.120 & 5.675 & 0.681 \\
\hline Amurskaya region & 0.096 & 6.872 & 0.657 \\
\hline Moscow region & 1.000 & 0.659 & 0.659 \\
\hline Samara region & 0.102 & 6.432 & 0.656 \\
\hline Altai region & 0.126 & 5.025 & 0.635 \\
\hline Astrakhan region & 0.099 & 5.982 & 0.591 \\
\hline Republic of Dagestan & 0.076 & 7.381 & 0.564 \\
\hline Saratov region & 0.081 & 4.977 & 0.403 \\
\hline Ulyanovsk region & 0.055 & 6.367 & 0.349 \\
\hline Bryansk region & 0.079 & 4.106 & 0.325 \\
\hline Belgorod region & 0.050 & 6.475 & 0.322 \\
\hline Kirov region & 0.088 & 3.380 & 0.298 \\
\hline Republic of Mordovia & 0.070 & 3.952 & 0.275 \\
\hline Chuvash Republic & 0.085 & 3.262 & 0.276 \\
\hline Jewish Autonomous region & 0.319 & 0.780 & 0.249 \\
\hline Sverdlovsk region & 0.132 & 1.883 & 0.248 \\
\hline Mari El Republic & 0.013 & 17.527 & 0.225 \\
\hline Rostov region & 0.135 & 1.628 & 0.219 \\
\hline Tyva Republic & 0.134 & 1.393 & 0.186 \\
\hline Krasnodar region & 0.040 & 4.022 & 0.160 \\
\hline Tula region & 0.044 & 3.747 & 0.164 \\
\hline Karachay-Cherkess Republic & 0.078 & 1.783 & 0.138 \\
\hline Kostroma region & 0.021 & 2.372 & 0.050 \\
\hline Republic of Adygea & 0.077 & 0.564 & 0.044 \\
\hline
\end{tabular}

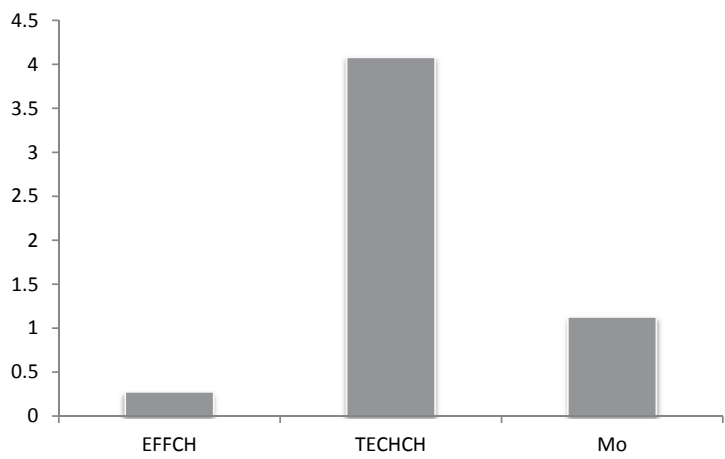

Figure 1. Averages of technical change and efficiency change.

Table III

DYNAMICS ASSESSMENT OF THE REGION INNOVATION SYSTEM DEVELOPMENT BASED ON THE MALMQUIST INDEX $M_{O}$

\begin{tabular}{lcc}
\hline \multirow{2}{*}{ Region Type } & \multicolumn{2}{c}{ Number of regions } \\
\cline { 2 - 3 } & Regions, units & Regions, \% \\
\hline Rapid growth $\left(M_{o}>2\right)$ & 21 & 26.25 \\
Growth $\left(2 \geq M_{o} \geq 1\right)$ & 26 & 32.50 \\
Lack of growth $\left(M_{o}<1\right)$ & 33 & 41.25 \\
\hline
\end{tabular}

The article presents a study of the functioning and efficiencies assessment of innovation systems. DEA model for the measurement of regional innovation systems' efficiency and Malmquist index was calculated.

Based on the calculation of the Malmquist index, we were able to conclude that positive spillovers and, accordingly, the positive effects of innovation policy over the 2005-2017 were shown by the regions with Malmquist index greater than 1. Over the study period, these regions showed a rise in the effectiveness of regional innovation systems, taking into 
[4] T. Broekel and T. Brenner, "Regional factors and innovativeness: an empirical analysis of four german industries," The Annals of Regional Science, vol. 47, no. 1, pp. 169-194, Aug 2011. [Online]. Available: https://doi.org/10.1007/s00168-009-0364-X

[5] K. Blind and H. Grupp, "Interdependencies between the science and technology infrastructure and innovation activities in german regions: empirical findings and policy consequences," Research Policy, vol. 28, no. 5, pp. 451-468, 1999. [Online]. Available: https: //EconPapers.repec.org/RePEc:eee:respol:v:28:y:1999:i:5:p:451-468

[6] R. Camagni and R. Capello, "Regional innovation patterns and the eu regional policy reform: Toward smart innovation policies," Growth and Change, vol. 44, 062013.

[7] P. McCann and R. Ortega-Argilés, "Modern regional innovation policy," Cambridge Journal of Regions, Economy and Society, vol. 6, no. 2, pp. 187-216, 05 2013. [Online]. Available: https: //doi.org/10.1093/cjres/rst007

[8] L. Leydesdorff, "The triple helix-university-industry-government relations: A laboratory for knowledge-based economic development," EASST Review, pp. 14-19, 1995.

[9] "The Russian Federal Service of State Statistics [Rosstat]," http://www.gks.ru/wps/wcm/connect/rosstat_main/rosstat/en/statistics/ science_and_innovations/science/\#, 25 July 2018.

[10] K. Tone, Advances in DEA Theory and Applications with Extensions to Forecasting Models. John Wiley \& Sons, N.Y., 2017.

The research was supported by Russian Science Foundation (project No. 19-18-00199).

\section{REFERENCES}

[1] A. Firsova and G. Chernyshova, "Analysis of efficiency of regional innovation systems taking into account the financing structure," in International Scientific Conference "Competitive, Sustainable and Secure Development of the Regional Economy: Response to Global Challenges" (CSSDRE 2018). Atlantis Press, 2018/05. [Online]. Available: https://doi.org/10.2991/cssdre-18.2018.86

[2] Z. Griliches, "Issues in Assessing the Contribution of Research and Development to Productivity Growth," Bell Journal of Economics, vol. 10, no. 1, pp. 92-116, Spring 1979. [Online]. Available: https://ideas.repec.org/a/rje/bellje/v10y1979ispringp92-116.html

[3] A. B. Jaffe, "Technological opportunity and spillovers of $\mathrm{r} \& \mathrm{~d}$ : Evidence from firms' patents, profits and market value," National Bureau of Economic Research, Working Paper 1815, 19861986. [Online]. Available: http://www.nber.org/papers/w1815

[11] S. Malmquist, "Index numbers and indifference surfaces," Trabajos de Estadistica, vol. 4, no. 2, pp. 209-242, Jun 1953. [Online]. Available: https://doi.org/10.1007/BF03006863

[12] D. W. Caves, L. R. Christensen, and W. E. Diewert, "The economic theory of index numbers and the measurement of input, output, and productivity," Econometrica, vol. 50, no. 6, pp. 1393-1414, 1982. [Online]. Available: http://www.jstor.org/stable/1913388

[13] M. J. Farrell, "The measurement of productive efficiency," Journal of the Royal Statistical Society. Series A (General), vol. 120, no. 3, pp. 253-290, 1957. [Online]. Available: http://www.jstor.org/stable/2343100

[14] R. Färe, S. Grosskopf, M. Norris, and Z. Zhang, "Productivity growth, technical progress, and efficiency change in industrialized countries," The American Economic Review, vol. 84, no. 1, pp. 66-83, 1994. [Online]. Available: http://www.jstor.org/stable/2117971

[15] W. Cooper, L. Seiford, and K. Tone, Data Envelopment Analysis: A Comprehensive Text with Models, Applications, References and DEASolver Software. Springer, 2007. 